
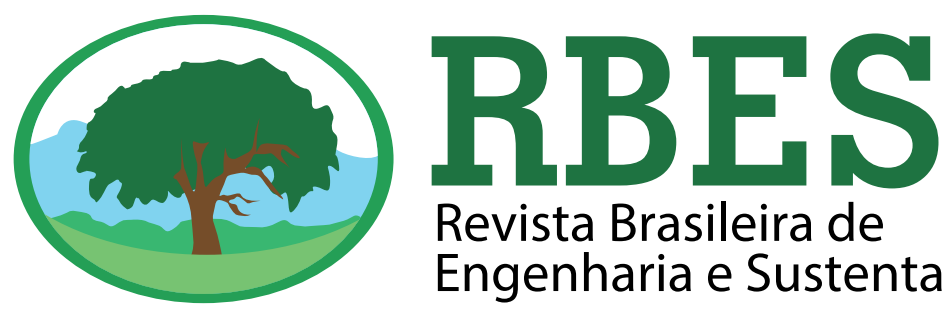

\title{
ARRANJO ESPACIAL DA UMIDADE DO SOLO, CARBONO ORGÂNICO E NEMATOFAUNA ÂS MARGENS DO RIO BRÍGIDÁ EM PARNAMIRIM - PE
}

SANTOS DA SILVA, E. P. F. ${ }^{1} ;$ PEDROSA, E. M. R. ${ }^{2} ;$ MELO, J. M. M. ${ }^{3} ;$ VICENTE, T, F. S. ${ }^{4} ;$ LOPES, ${ }^{5}{ }^{5} ;$ MORAIS, T. F. ${ }^{6} ;$ FEITOSA E SILVA, D.H. ${ }^{6}$

'Graduando em Agronomia na UFRPE. Bolsista PET AgroEnergia/IC. Rua Dom Manuel de Medeiros, s/n, Dois Irmãos - CEP:52171-900Recife/PE.

${ }^{2}$ Professora Titular do Departamento de Engenharia Agrícola/UFRPE. Rua Dom Manuel de Medeiros, s/n, Dois Irmãos - CEP:52171-900Recife/PE.

${ }^{3}$ Doutoranda em Engenharia Agrícola UFRPE. Rua Dom Manuel de Medeiros, s/n, Dois Irmãos - CEP:52171-900-Recife/PE.

${ }^{4}$ Doutora em Engenharia Agrícola e bolsista PNPD/CAPES pelo departamento de Engenharia Agrícola UFRPE. Rua Dom Manuel de Medeiros, s/n, Dois Irmãos - CEP:52171-900-Recife/PE.

${ }^{5}$ Professor do IFBA. Km 14, BR-349, S/N - Zona Rural, Bom Jesus da Lapa - BA, CEP:47600-000.

${ }^{6}$ Graduando em Agronomia na UFRPE. Bolsista PIBIC/IC. Rua Dom Manuel de Medeiros, s/n, Dois Irmãos - CEP:52171-900-Recife/PE.

Palavras-chave: Geoestatística, Mata Ciliar, Nematofauna, Semiárido.

\section{Resumo}

O Semiárido Pernambucano é uma região singular, que ao longo do tempo vêm sendo cada vez mais utilizado pelo homem, causando problemas ambientais, pela remoção da vegetação nativa e manejo inadequado dos solos pela agricultura intensiva. Dentre muitas alternativas para avaliar a qualidade dos solos, os nematoides podem ser utilizados como bioindicadores por serem adaptados à situação natural edáfica de diferentes ambientes e por serem extremamente sensíveis à mudança destes sistemas. A seguinte pesquisa foi realizada no Município de Parnamirim, PE, com o objetivo de avaliar a comunidade de nematoides e sua distribuição espacial, da umidade e do teor de carbono orgânico no solo em área ripária na Bacia Hidrográfica do Rio Brígida. Os nematoides bacteriófagos foram dominantes na área seguido por parasitos de planta, a via de decomposição da matéria orgânica ocorre por via bacteriana. Maiores níveis de umidade, carbono do solo e populações de grupos tróficos foram encontrados predominantemente às margens do rio, porém a maior concentração de diversidade trófica ocorreu na região central da área de estudo.

\section{SPATIAL ARRANJEMENT OF SOIL MOISTURE, ORGANIC CARBON AND NEMATODE COMMUNITY IN THE BRIGIDA RIVER BANK IN PARNAMIRIM - PE}

Keywords: Geoestatistics,

Riparian Forest, soil nematode, Semiarid.

\section{Abstract}

The Semi-Arid in Pernambuco is a unique region, which over time has been increasingly used by man, causing environmental problems by removal of native vegetation and inadequate soil management by intensive agriculture. Among many alternatives to assess soil quality, nematodes can be used as bioindicators because they are adapted to different soil environments and because they are extremely sensitive to changes in these systems. The following research was carried out in the Municipality of Parnamirim, PE, in order to describe spatial distribution of nematode community, moisture and organic carbon content in the soil in a riparian area of the Brígida river bank. The bacterivores nematodes were dominant in the area followed by plant parasites, the organic matter decomposition pathway occurs through bacterial. High levels of moisture, soil carbon and trophic group populations were found predominantly on the margins of the river, althoug the highest concentration of trophic diversity occurred in the central region of the study area. 


\section{INTRODUC̣ÃO}

O Semiárido Pernambucano é caracterizado por forte escassez hídrica, altas temperaturas e pela vegetação Caatinga (SILVA et al., 2018). Além disso, os solos do sertão apresentam baixa fertilidade, má drenagem e pouca profundidade, dificultando as atividades agrícolas. No entanto, a retirada da vegetação nativa para a implantação da agricultura auxilia na erosão e desertificação culminando na degradaçáo dos solos (BRASILEIRO, 2009; NASCIMENTO et al, 2018).

A avaliação da qualidade dos solos pode ser efetuada por meio dos nematoides agindo com bioindicadores (MOURA; FRANZENER, 2017). Pois, são organismos abundantes no ecossistema do solo, são classificados em grupos tróficos (bacteriófagos, micófagos, parasitos de plantas, onívoros e predadores) e são facilmente observáveis e quantificáveis usando técnicas laboratoriais simples (BONGERS; FERRIS, 1999; ZAVISLAK et al., 2017), o que os torna sensíveis a diferentes respostas ambientais.

Variados estudos foram e vêm sendo desenvolvidos acerca do comportamento dos nematoides em ambientes distintos. Gutiérrez et al (2016) em estudo sobre diferentes usos do solo, relacionaram Acrobeloides (bacteriófagos) a ambientes industriais com metais pesados (ex: $\mathrm{Cd}$, $\mathrm{Pb}$ e $\mathrm{Cr}$ ), uma vez que, são nematoides que possuem ciclo de vida curto, se reproduzem rápido e são resistentes em ambientes que sofreram distúrbios (ex: áreas industriais com metais pesados).

Segundo Silva et al (2020), a mudança da vegetação nativa da Caatinga para a implantação de agroecossistemas interferiu negativamente na população de nematoides bacteriófagos e onívoros, demonstrando diminuição da população da primeira para a segunda área. Porém, estudos relacionando a comunidade dos nematoides e as propriedades do solo na região semiárida do Nordeste e em Pernambuco, ainda são escassos.

Compreender as interações entre fatores que compóem solos de ecossistemas complexos e decompositores é de grande importância, para saúde ambiental desses sistemas. Diversos trabalhos relatam que a umidade e a matéria orgânica do solo são os fatores que mais afetam a distribuição da comunidade total de nematoide tanto em ecossistemas naturais como em ecossistemas agrícolas (ZHAO et al., 2014; CARDOSO et al., 2015; VANDEGEHUCHTE et al., 2015; GUTIÉRREZ et al., 2016).

Sabe-se que existem relaçóes estreitas entre nematoides e outros microrganismos, como fungos e bactérias, dentro da cadeia alimentar do solo, o aumento de carbono orgânico no solo pode aumentar a atividade microbiana e, em seguida, aumentar a base alimentar de nematoides de vida livre, bacteriófagos e micófagos e por fim, onívoros e predadores (JIANG et al., 2017). Entender o comportamento desses microrganismos em um ambiente com baixa precipitaçáo pode auxiliar no manejo do solo e identificar áreas degradadas por ação antrópica. Desta forma, o objetivo do estudo foi avaliar a comunidade de nematoides e sua distribuição espacial, da umidade e do teor de carbono orgânico no solo em área ripária com predominância de algaroba na Bacia Hidrográfica do Rio Brígida.

\section{MATERIAL E MÉTODOS}

\section{Área de Estudo}

O estudo foi conduzido no município de Parnamirim-PE (coordenadas $08^{\circ} 05^{\prime} 08^{\prime \prime}$ de latitude Sul e 39 34’27" de longitude Oeste). A vegetação dominante é a Caatinga Hiperxerófila e o clima é do tipo Tropical Semiárido, com chuvas de verão. $\mathrm{O}$ período chuvoso se estende de novembro a abril. A precipitação média anual é de 431,8 mm.

A área de estudo está localizada na Estação de Agricultura Irrigada de Parnamirim da UFRPE (EAIP/ UFRPE) situada às margens do rio Brígida que possui regime fluvial efêmero. O histórico da área é de intenso uso agrícola e atualmente a vegetação natural de mata ciliar encontra-se, em sua grande maioria, substituída pela espécie vegetal exótica Prosopis juliflora (Sw) DC (algaroba).

\section{Amostragem do solo}

A amostragem foi realizada em novembro de 2018 em uma das margens do Rio Brígida, a jusante da barragem do Fomento, em uma malha de 50 x $40 \mathrm{~m}$, com espaçamento de $10 \mathrm{~m}$ entre os pontos, totalizando 30 amostras de solo. Foram coletadas amostras na camada de 0,0-0,3 $\mathrm{m}$ para as análises de umidade, de matéria orgânica e de nematoides (Figura 1). 


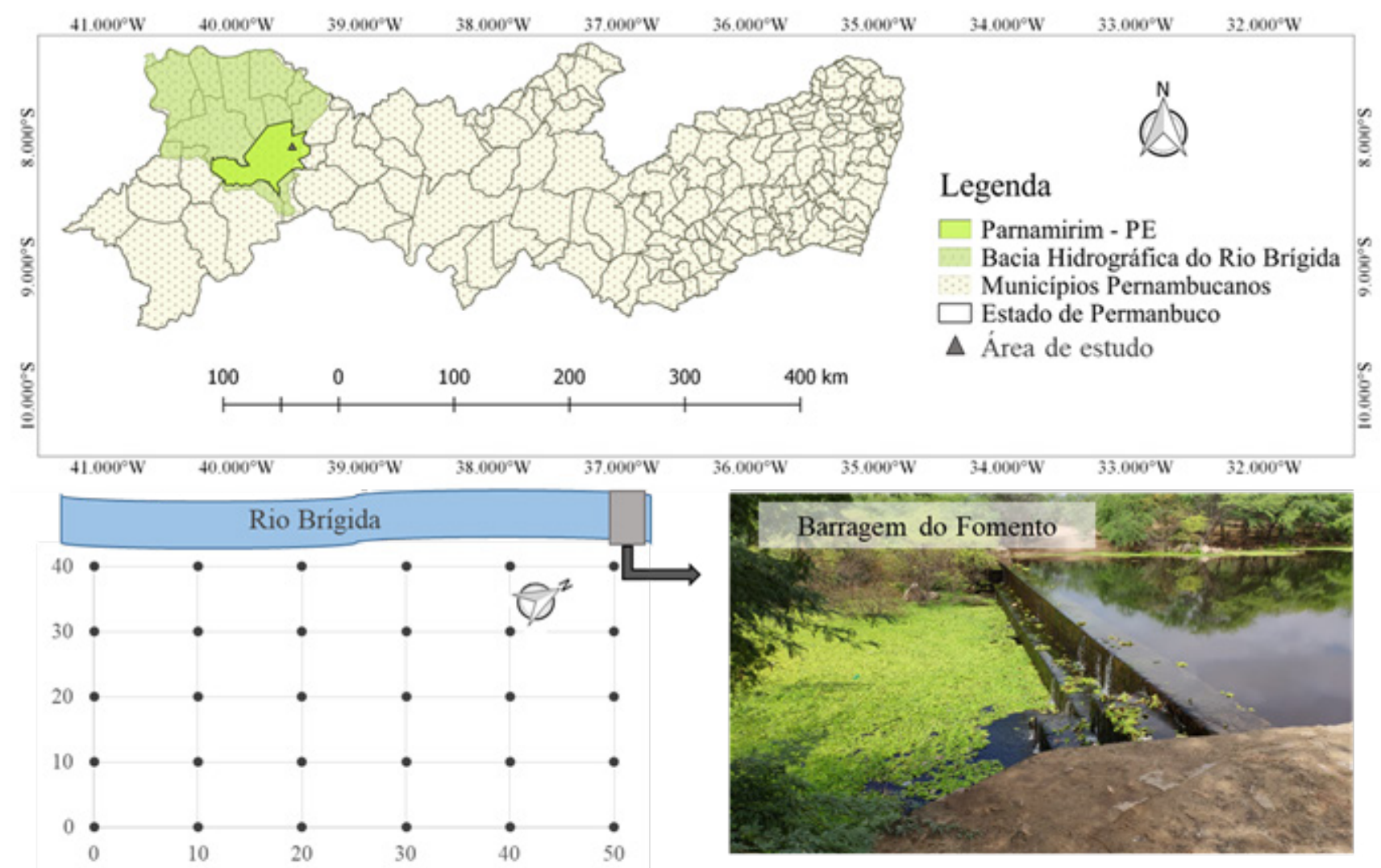

Figura 1. Mapa com localização do município de Parnamirim/PE, local do experimento e desenho da malha de amostragem.

\section{Análise das propriedades do solo}

A umidade do solo foi determinada pelo método gravimétrico, onde as amostras foram pesadas antes e após serem colocadas em estufa a $105^{\circ} \mathrm{C}$ (TEIXEIRA et al., 2017). O carbono orgânico total (COT) foi mensurado pela oxidação da matéria orgânica com dicromato de potássio por meio do processo de titulação com sulfato ferroso amoniacal (YEOMANS E BREMNER, 1988).

\section{Análises de nematoides no solo}

Amostras de $300 \mathrm{~cm}^{3}$ de solo foram homogeneizadas e processadas para extração dos nematoides, utilizando o método da flotação centrífuga (JENKINS, 1964). A estimativa populacional foi obtida através da contagem em lâmina de Peters, com o auxílio de um microscópio óptico, em duas repetições. Os resultados foram computados em número de espécimes por 300 $\mathrm{cm}^{3}$ de solo.

Para o estudo da estrutura trófica, os nematoides foram classificados quanto ao hábito alimentar em cinco grupos tróficos (parasitos de planta, bacteriófagos, micófagos, predadores e onívoros), baseado na morfologia do estoma e esôfago (YEATES et al., 1993). Em seguida foram calculados os seguintes índices ecológicos representados pelas fórmulas abaixo: Índice de dominância de Simpson

$$
\lambda=\sum(P i)^{2} \mathrm{Eq},(1)
$$

Em que:

Pi: Abundância relativa de cada espécie, calculada pela proporção dos indivíduos de uma espécie pelo número total dos indivíduos na comunidade ni $/ \mathrm{N}$;

$\mathrm{N}$ : Número total dos indivíduos na comunidade; ni: Número de indivíduos de uma espécie.

Índice de diversidade de Shannon-Weaver (H')

$$
H^{\prime}=-\sum p i *(\ln P i) \mathrm{Eq},(2)
$$

\section{Em que:}

Pi: Abundância relativa de cada espécie, calculada pela proporção dos indivíduos de uma espécie pelo número total dos indivíduos na comunidade ni/N;

$\mathrm{N}$ : Número total dos indivíduos na comunidade; ni: Número de indivíduos de uma espécie. 
Índice de diversidade trófica (T)

$$
T=\frac{1}{\sum(p i)^{2}} \text { Eq, (3) }
$$

\section{Em que:}

Pi: Abundância relativa de cada espécie, calculada pela proporção dos indivíduos de uma espécie pelo número total dos indivíduos na comunidade ni/N;

$\mathrm{N}$ : Número total dos indivíduos na comunidade;

ni: Número de indivíduos de uma espécie

Razão micófagos/bacteriófagos

$$
R=\frac{M i}{B a} \mathrm{Eq},(4)
$$

Em que:

Mi: Nematoides micófagos

Ba: Nematoides bacteriófagos

\section{Análise estatística}

Os dados de umidade, carbono orgânico total do solo, grupos tróficos de nematoides e índices ecológicos foram submetidos à estatística descritiva (média, a mediana, valores máximos e mínimos, a variância, o desvio padrão, os coeficientes de assimetria, curtose e de variaçáo). Em seguida foi utilizado o teste Kolmogorov-Smirnov de 5\% de significância para avaliar a normalidade dos dados. Apesar de a normalidade não ser exigência na geoestatística, essa permite observar maior precisão das estimativas da krigagem por meio de seus valores médios (Cressie, 1991). Os dados não normais foram transformados para $\log (\mathrm{x}+1)$.

A análise de variabilidade espacial foi realizada por meio de técnica geoestatística, através do ajuste do semivariograma clássico (JOURNEL, 1989). Com base na pressuposição de estacionariedade foi calculada a semivariância $\gamma$ (h) pela Eq. 5, conforme Matheron (1963):

$$
\gamma(h)=\frac{1}{2 N(h)} \sum_{i=1}^{N(h)}(Z(x+h)-Z(x))^{2} \mathrm{Eq},(5)
$$

Em que:

$\mathrm{N}(\mathrm{h})$ - número de pares

$\mathrm{Z}(\mathrm{x}+\mathrm{h})$ e $\mathrm{Z}(\mathrm{x})$ - valores da propriedade de interesse nas locações $(x+h)$ e $(x)$
Foram testados os modelos esférico, exponencial e gaussiano, de acordo com Deutsch et al. (1998). Através do ajuste do modelo matemático aos valores calculados, foram estimados os coeficientes do modelo teórico para o semivariograma: o efeito pepita $(\mathrm{C} 0)$; o patamar $(\mathrm{C} 0+\mathrm{C} 1)$; e o alcance (a).

O grau de dependência espacial (GDE) foi classificado de acordo com Cambardella et al. (1994), que é dado por $\mathrm{GDE}=\mathrm{C} /[\mathrm{C}+\mathrm{C} 0]$ e sugere dependência forte $<25 \%$; dependência moderada entre 25 e $75 \%$; e dependência fraca $>75 \%$.

Os modelos esférico, exponencial e gaussiano ajustados aos semivariogramas foram submetidos ao processo de validação cruzada "jack-knifing (VAUCLIN et al., 1983), considerando os valores da média próximo a zero e do desvio padrão próximo a um. Também foram avaliados os valores de $\mathrm{R}^{2}$. Em seguida foi efetuada elaboração de mapas a partir de estimativa dos dados em locais não amostrados pelo método da krigagem. Os mapas foram confeccionados utilizando o Software SURFER ${ }^{\oplus}$, versão 13.0.

\section{RESULTADOS E DISCUSSÃO}

\section{Comunidade de nematoides}

Os nematoides de vida livre representaram 74,6\% dos nematoides identificados na área, seguido de parasitos de planta com dominância de 25,4\% (Tabela 1). Dentre os nematoides de vida livre, os bacteriófagos foram dominantes correspondendo a $55 \%$ dos nematoides identificados, seguidos por onívoros com 16,2\% e micófagos com 3,41\%. Não foram identificados nematoides predadores na área.

Em estudo desenvolvido sobre a comunidade de nematoides em cinco áreas no Cerrado, onde a Mata de Galeria apresentou maior número de nematoides, os parasitos de planta foram dominantes, seguidos dos bacteriófagos, onívoros, micófagos e predadores, respectivamente (RODRIGUES, 2011).

A abundância de nematoides parasitos de planta foi justificada pela abundância de plantas (arbóreas e herbácea), cuja concentração de raízes fornece mais alimentos ao parasito (RODRIGUES, 2011). Contudo, diferentemente da Mata de Galeria, a região estudada é composta em sua maioria pela algaroba (Prosopis juliflora), que são árvores cujas raízes não se 
penetram facilmente em comparação a uma planta herbácea.

Os nematoides bacteriófagos se alimentam de bactérias que decompóem a matéria orgânica do solo. Portanto, a dominância deste grupo trófico especificamente está associada a decomposição da matéria orgânica (MOURA; FRANZENER, 2017;
YADAV; PATIL; KANWAR, 2018).

Os bacteriófagos possuem curto ciclo de vida, produzem grande quantidade de ovos, resultando numa alta taxa populacional em ambientes com alta atividade bacteriana. Possuem alta atividade metabólica, são relativamente tolerantes aos produtos da decomposiçáo da matéria orgânica no solo (BONGERS, 1990).

Tabela 1. Abundância, média, desvio padrão e dominância dos grupos tróficos de nematoides do solo em um fragmento de mata ciliar da Bacia Hidrográfica do Rio Brígida, Parnamirim, PE

\begin{tabular}{ccccc}
\hline Grupo trófico & Abundância & Média & DP & Dominância (\%) \\
\hline Vida livre & 18492 & 616,4 & 551,3 & 74,6 \\
\hline Bacteriófagos & 13630,5 & 454,35 & 421,05 & 54,99 \\
Micófagos & 845,5 & 28,18 & 32,75 & 3,41 \\
Onívoros & 4016 & 133,87 & 143,66 & 16,2 \\
\hline Parasitos de planta & 6296 & 209,87 & 286,56 & 25,4 \\
\hline Total de Nematoides & 24788 & & & $100 \%$ \\
\hline
\end{tabular}

Legenda: DP-Desvio padrão

\section{Estatística Descritiva}

O coeficiente de variação $(\mathrm{CV})$ é considerado baixo quando inferior a $10 \%$, médio entre 10 e $20 \%$, alto entre 20 e $30 \%$ e muito alto quando superior a $30 \%$ (PIMENTEL GOMES, 2000). Os valores encontrados demostram que a dispersão dos dados é considerada alta e muito alta, exceto o índice de diversidade de Shannon (18,8\%) com CV baixo (Tabela 2).

$\mathrm{O} C V$ indica o quanto as variáveis são homogêneas ou heterogêneas (Tabela 2). A alta variabilidade dos grupos tróficos e dos índices, oriundos dos nematoides, é atribuída a reprodução dos microrganismos que não é constante, tornando sua variação heterogênea na área. Portanto, é comum encontrar CV alto em estudos com nematoides (CARDOSO et al., 2011).

Outro fator a considerar é a declividade natural que ocorre às margens de rios. Devido ao processo de drenagem presente nesses cursos, que, em conjunto com a lixiviação de partículas, nutrientes e organismos do solo, fazem essas áreas terem aspecto heterogêneo ao longo de sua extensão, influenciando nas variáveis bióticas e abióticas (GOENSTER-JORDAN et al, 2018).

O teste de aderência a normalidade KolmogorovSmirnov (KS) mostrou que apenas os nematoides parasitos de planta apresentaram distribuição não normal (Tabela 2), revelados pelos menores valores do maior erro em relação ao valor crítico $(0,24$, para $\alpha$ = 0,05). Dados que apresentam distribuição normal fornecem maior precisão nas estimativas da krigagem, no entanto, a geoestatística pode ser efetuada em dados que não apresentam distribuição normal.

Além do teste de aderência, pode-se ter uma ideia da normalidade dos dados observando a variação entre os valores da média e mediana, quanto mais próximos menor a variaçáo dos dados, e também dos coeficientes de assimetria e curtose, o primeiro avalia o grau de desvio e o segundo o grau de achatamento de uma curva. Os valores da assimetria ficam em torno de 0 e a curtose em torno 3, no entanto, valores maiores significam que os dados têm comportamento diferente de uma curva de distribuição normal.

Ao observar o comportamento dos dados (Tabela 2) nota-se, como já citado, que os nematoides parasitos de planta possuem distribuição não normal, ao contrário das demais variáveis avaliadas. Também é visto que os valores das médias e medianas de micófagos e onívoros não estáo próximos e mesmo assim passaram no teste de normalidade.

A normalidade dos dados é fator importante para se avaliar a distribuição espacial dos dados, no entanto, a relação de fatores ambientais com os nematoides e a reprodução destes microrganismos influenciam na 
distribuição espacial dos nematoides. Sendo assim, de Simpson, mostram que existe poucas espécies de como apenas os parasitos de planta não apresentaram nematoides comuns distribuídas na área, independente distribuição normal foi efetuada a análise geoestatística da região. Já a razão micófagos/bacteriófagos $(\mathrm{Mi} / \mathrm{Ba})$ em todos os grupos tróficos.

Os valores indicados pelo índice de dominância orgânica ocorre por via bacteriana.

Tabela 2. Estatística descritiva das variáveis analisadas e calculadas de um solo em um fragmento de mata ciliar da Bacia Hidrográfica do Rio Brígida, Parnamirim, PE

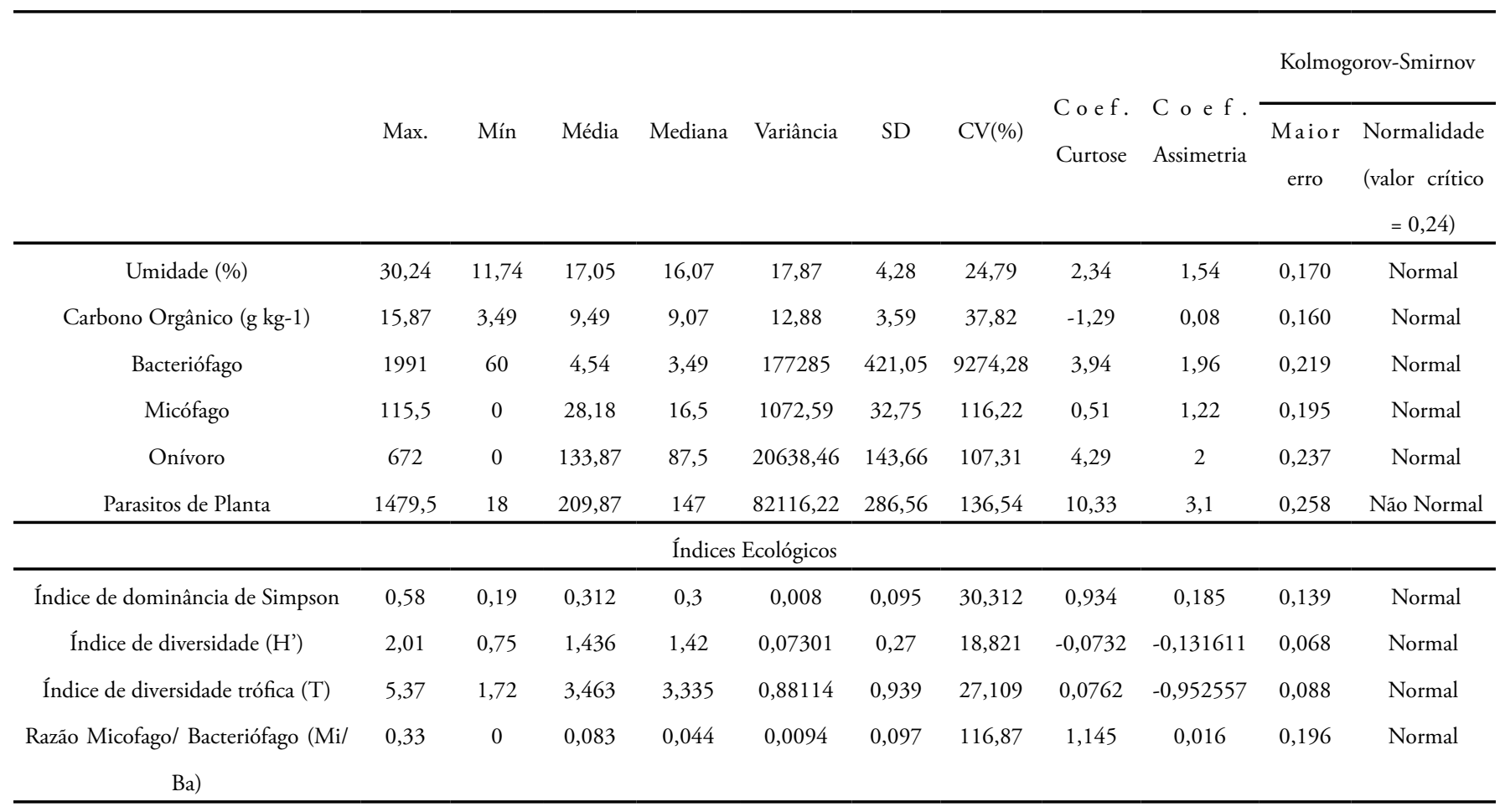

Legenda: Max - valor máximo, Min - valor mínimo, DP -Desvio padrão, CV - Coeficiente de variação

\section{Distribuição espacial de grupos tróficos,} índices ecológicos e variáveis do solo

A avaliação da estrutura da dependência espacial foi realizada por meio dos parâmetros dos semivariogramas teórico (Tabela 3). A razão $\mathrm{Mi} / \mathrm{Ba}$ foi a única que apresentou efeito pepita puro (EPP), ou seja, provavelmente o espaçamento utilizado para amostragem não foi suficiente para detectar distribuição espacial para esta variável e também, desta forma não é possível efetuar o mapeamento da área para esta variável, já os demais parâmetros apresentaram distribuição espacial. O modelo exponencial se ajustou melhor aos dados.

O índice de Simpson $(\kappa)$ apresentou o menor alcance $(19,05 \mathrm{~m})$, enquanto, o índice de ShannonWeaver $\left(\mathrm{H}^{\prime}\right)$ apresentou o maior $(143,97 \mathrm{~m}$ ) (Tabela 3). Em outras palavras, o alcance seria a distância na qual se pode detectar a distribuição espacial e pode variar de acordo com a variável estudada, com o manejo aplicado e com o tempo.

Quase todas as variáveis apresentaram GDE forte, exceto os nematoides parasitos de planta e o índice de diversidade que apresentaram GDE moderado. Cambardella et al (1994) descreve que quanto menor o grau de dependência (GDE) maior a dependência espacial entre as amostras, em outros termos, todas as variáveis que apresentaram GDE forte possuem maior dependência espacial.

\section{Mapas de grupos tróficos, índices ecológicos e variáveis do solo}

Nos mapas pode-se observar as regiōes de maior densidade populacional de nematoides, assim como, de concentrações das demais variáveis (Figura 2). Além da umidade, bacteriófagos, onívoros, parasitos de planta e o índice de Shannon-Weaver apresentam os maiores valores às margens do rio, já o carbono orgânico do solo possui distribuição mais homogênea na área. 
Tabela 3. Parâmetros de semivariograma para as propriedades do solo, os grupos tróficos de nematoides e os índices ecológicos

\begin{tabular}{|c|c|c|c|c|c|c|c|c|c|}
\hline & \multirow{2}{*}{$\begin{array}{c}\text { M o d e lo } \\
\text { Ajustado }\end{array}$} & \multirow{2}{*}{$\mathrm{C} 0$} & \multirow{2}{*}{$\mathrm{C} 0+\mathrm{C} 1$} & \multirow{2}{*}{$\mathrm{A} 0$} & \multirow{2}{*}{ 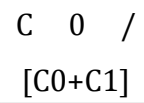 } & \multirow{2}{*}{$r^{2}$} & \multirow{2}{*}{ GDE } & \multicolumn{2}{|c|}{ Jack-Knifing } \\
\hline & & & & & & & & Média & DP \\
\hline Umidade & Gaussiano & 7.44 & 30.03 & 73.75 & 0.248 & 0.994 & Forte & 0.101 & 0.975 \\
\hline Carbono Orgânico & Exponencial & 0.35 & 12.23 & 22.74 & 0.029 & 0.274 & Forte & 0.043 & 0.863 \\
\hline Bacteriófago & Esférico & 20400 & 314700 & 58.17 & 0.065 & 0.981 & Forte & 0.174 & 0.908 \\
\hline Micófago & Exponencial & 130 & 1171 & 23.7 & 0.111 & 0.868 & Forte & 0.273 & 1.037 \\
\hline Onívoro & Gaussiano & 11600 & 54300 & 80.86 & 0.214 & 0.984 & Forte & 0.163 & 1.078 \\
\hline Parasitos de Planta & Gaussiano & 32700 & 116500 & 68.32 & 0.281 & 0.937 & Moderado & 0.056 & 1.045 \\
\hline \multicolumn{10}{|c|}{ Índices Ecológicos } \\
\hline $\begin{array}{l}\text { Índice de dominância de } \\
\qquad \text { Simpson }(\lambda)\end{array}$ & Exponencial & 0.0005 & 0.0092 & 19.05 & 0.054 & 0.661 & Forte & 0.146 & 0.96 \\
\hline Índice de diversidade & Exponencial & 0.0491 & 0.1157 & 143.97 & 0.424 & 0.862 & Moderado & 0.132 & 0.987 \\
\hline $\begin{array}{c}\text { Índice de diversidade } \\
\text { trófica (T) }\end{array}$ & Esférico & 0.064 & 0.947 & 19.2 & 0.068 & 0.965 & Forte & 0.121 & 1.004 \\
\hline $\begin{array}{l}\text { Razão } \quad \text { Micófago/ } \\
\text { Bacteriófago (Mi/Ba) }\end{array}$ & ЕРP & - & - & - & - & - & - & - & - \\
\hline
\end{tabular}

C0- efeito pepita, C-Patamar, C1-Contribuição, A0-Alcance, $r^{2}$-coeficiente de determinação, GDE-grau de dependência espacial, DP-Desvio padrão em Jack-Knifing

Os bacteriófagos (Figura 2C), grupo dominante na área, concentram-se em uma região próxima ao rio com maiores valores de carbono orgânico (Figura 2B) e umidade (Figura 2A). Os bacteriófagos têm sido associados a solos úmidos e com maior diversidade vegetacional, favorecidos pela matéria orgânica oriundas da vegetação (BR IAR et al., 2012).

A região com maioıcs valores do índice de dominância de Simpson ( ） (Figura 2G) se localiza entre as regióes onde se encontram os parasitas de plantas (Figura 2F) e os bacteriófagos. $\mathrm{O}$ índice de dominância de Simpson foi desenvolvido para atribuir maior peso às espécies mais comuns (MELO, 2008), e essas espécies pertencem aos dois grupos dominantes na área do presente estudo.

O índice de diversidade de Shannon (H') (Figura $2 \mathrm{H}$ ), possui maior concentração da margem do rio para o centro da área estudada, coincidindo com a regiáo com maior densidade populacional de micófagos (Figura 4E). Esse índice caracteriza-se por atribuir peso igual a espécies raras, o que ocorre com alguns gêneros de micófagos na área estudada.

$\mathrm{O}$ índice de diversidade trófica (T) (Figura 2I) possui maiores valores na regiáo central do mapa, onde a concentração de do índice de shannon $(\mathrm{H})$

e micófagos é maior e a dos demais grupos tróficos é menor. Devido, exatamente a possuir menor população de nematoides nessa regiáo do mapa. Podese observar que é uma regiáo onde se encontra espécies raras (índice de shannon).

\section{CONLUSÃO}

1. Os nematoides bacteriófagos são dominantes na área estudada;

2. A decomposição da matéria orgânica no solo ocorre por via bacteriana;

3. A maior concentração dos nematoides bacteriófagos, onívoros e parasitos de planta ocorre em áreas mais próxima ao rio;

4. A distribuição de micófagos ocorre principalmente na região central da área;

5. Os maiores valores de umidade são encontrados nas proximidades do rio, assim como o carbono do solo, que possui distribuição mais homogênea na área;

6. O índice de Simpson e os de shannon e de diversidade trófica se posicionam em regióes opostas no mapa;

7. Os nematoides bacteriófagos, parasitos de planta, onívoros e micófagos possuem maiores valores nas mesmas regióes que a umidade e o carbono orgânico do solo. 
A.

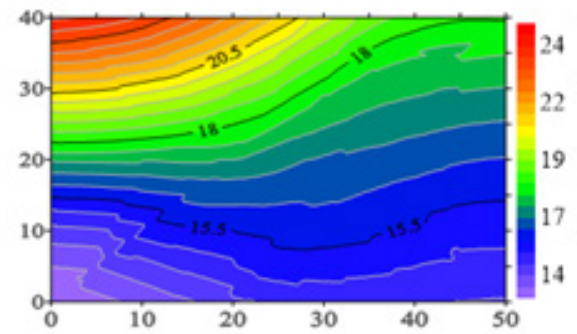

D.
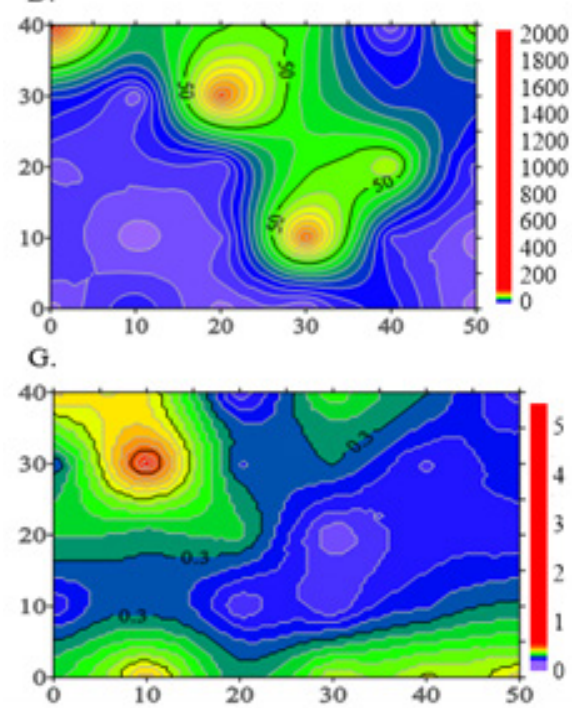

B.

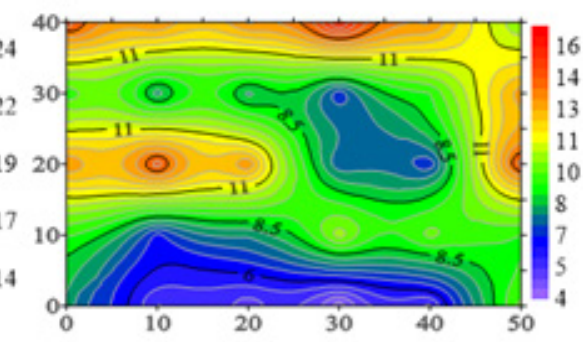

E.
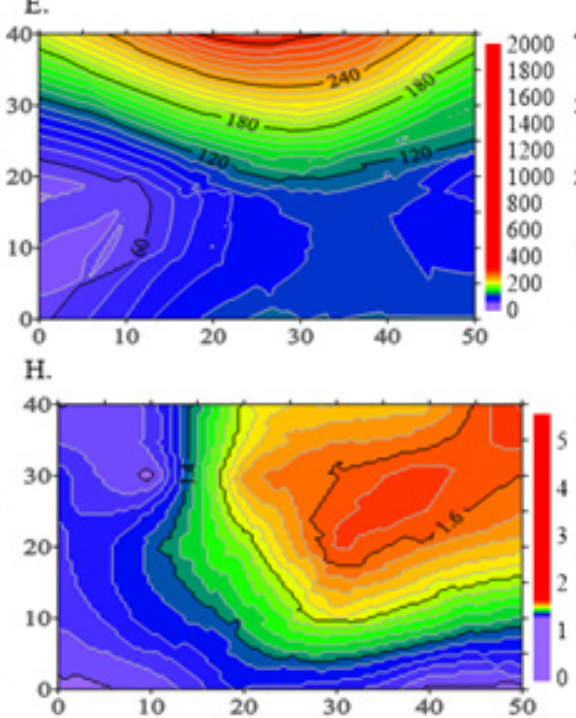

C.

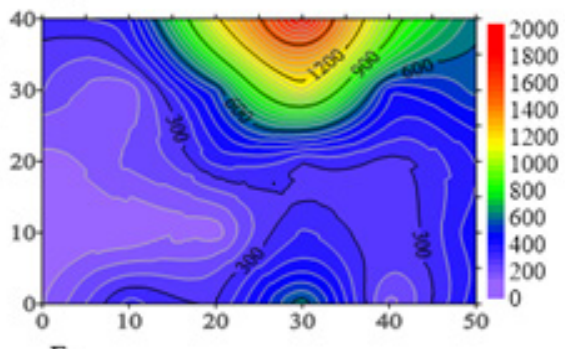

F.
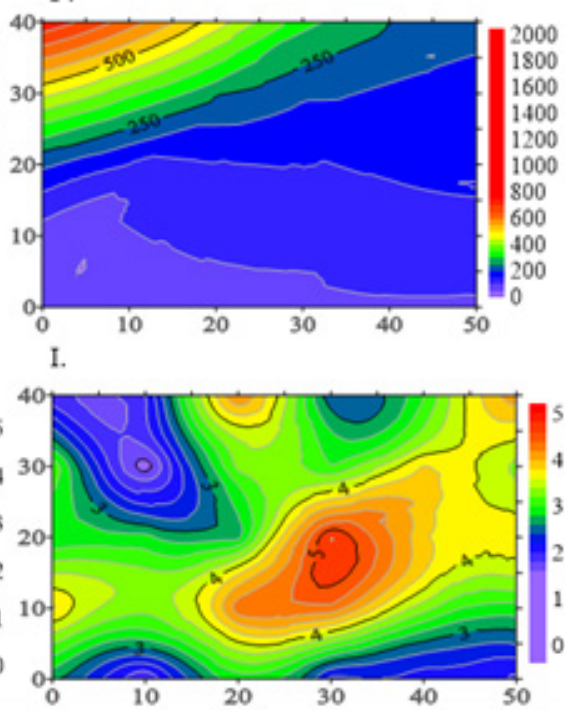

Figura 2. Mapas de contorno (krigagem) para a umidade (\%) (A), carbono orgânico $\left(\mathrm{g} \mathrm{kg}^{-1}\right)(B)$, nematoides (em número por $\mathrm{cm}^{3}$ de solo) bacteriófagos (C), micófagos (D), onívoros (E), parasitos de planta (F), índices de dominância de Simpson- $\boldsymbol{\lambda}(\mathrm{G})$, de diversidade de Shannon-Weaver- $H^{\prime}(H)$, de diversidade trófica-T (I)

\section{AGRADECIMENTOS}

Os autores agradecem a CAPES, ao CNPq, a FACEPE pelo financiamento da pesquisa, ao Programa de Engenharia Agrícola (PGEA/UFRPE) e ao Programa de Educação Tutorial da UFRPE (PET AgroEnergia).

\section{LITERATURA CITADA}

BONGERS, T. The maturity index: an ecological measure of environmental disturbance based on nematode species composition. Oecologia, v.83, n.1, p.14-19, 1990.

BONGERS, T.; FERRIS, H. Nematode community structure as a bioindicator in environmental monitoring. Trends in Ecology \& Evolution, v.14, n.6, p.224-228, 1999.

BRASILEIRO, R. S. Alternativas de desenvolvimento sustentável no semiárido nordestino: da degradação à conservação. Scientia Plena, v.5, n.5, p.1-12, 2009.
BRIAR, S. S.; CULMAN, S. W.; YOUNGMATHEWS, A.; JACKSON, L. E.; FERRIS, H. Nematode community responses to a moisture gradient and grazing along a restored riparian corridor. European Journal of Soil Biology, v.50, p.32-38, 2012.

CAMBARDELLA, C. A.; MOORMAN, T. B.; NOVAK, J. M.; PARKIN, T. B.; KARLEN, D. L.; TURCO, R. F.; KONOPKA, A. E. Field-scale variability of soil properties in central Iowa soils. Soil Science Society America Journal, v.58, p.1501-1511, 1994.

CARDOSO, M. O.; PEDROSA, E. M. R.; ROLIM, M. M.; SILVA, E. F. F; BARROS, P. A. Effects of soil mechanical resistance on nematode community structure under conventional sugarcane and remaining of Atlantic Forest. Environmental Monitoring and Assessment, v.184, n.6, p.3529-3544, 2011. 
CARDOSO, M. O.; PEDROSA, E. M. R.; FERRIS, H.; ROLIM, M. M.; VICENTE, T. F. S.; DAVID, M. F. L. Comparing sugarcane fields and forest plots: the effect of disturbance on soil physical properties and nematode assemblages. Soil Use and Management, v.31, p.397-407, 2015.

CRESSIE, N. Statistics for spatial data. New York: Iowa State University, 1991. 920p.

DEUTSCH, C. V.; JOURNEL, A. G. GSLIB Geostatistical Software Library and User's Guide. 2.ed. New York: Oxford University Press, 1998. 369p.

GOENSTER-JORDAN， S.; JANNOURA, R.; JORDAN, G.; BUERKERT, A.; JOERGENSEN, R. G. Variabilidade espacial das propriedades do solo na planície de inundação de um oásis de rio nas montanhas Altay da Mongólia. Geoderma, v.330, p.99-106, 2018.

GUTIÉRREZ, C.; FERNANDÉZ, C.; ESCUER, M.; CAMPOS-HERRERA, R.; RODRÍGUEZ, M. E. B.; CARBONELL, G; MARTÍN, J. A. R. Effect of soil properties, heavy metals and emerging contaminants in the soil nematodes diversity. Environmental Pollution, v.213, p.184-194, 2016.

JENKINS, W. R. A rapid centrifugal-flotation technique for separating nematodes from soil. Plant Disease Reporter, Iowa-United States, v.48, p.692, 1964.

JIANG, Y., LIU, M., ZHANG, J., CHEN, Y., CHEN, X., CHEN, L., ET AL. Nematode grazing promotes bacterial community dynamics in soil at the aggregate level. The ISME Journal, v. 11, p.2705-2711, 2017.

JOURNEL, A. G. Fundamentals of Geostatistics in Five Lessons. 8.ed. Washington: Short Courses in Geology, 1989. 40p.

MATHERON, G. Principles of Geostatistics. Economic Geology, v.58, n.8, p.1246-1266, 1963.
MOURA, G. S.; FRANZENER, G. Biodiversity of nematodes biological indicators of soil quality in the agroecosystems. Arquivos do Instituto Biológico, v.84, p.1-8, 2017.

MELO, A. S. O que ganhamos 'confundindo' riqueza de espécies e equabilidade em um índice de diversidade? Biota Neotropica. v.8, n.3, p.21-27, 2008.

NASCIMENTO, S. P. G.; SILVA, J. M.; SANTOS, E. O.; SILVA, P. V. M.; SANTOS, J. R. U.; SANTOS, T. M. C. Impactos ambientais da produçáo vegetal no processo de desertificação do semiárido alagoano: o caso de Ouro Branco-AL. Revista Ciência Agrícola, v.16, p.31-35, 2018.

PIMENTEL GOMES, F. Curso de Estatística Experimental. 14.ed. Piracicaba: Degaspari. 2000. $477 \mathrm{p}$.

RODRIGUES, C. S. Comunidades de nematides associadas às principais fitofisionomias do cerrado do parque nacional de Brasília. 2011. 67f. Dissertação (Mestrado em Fitopatologia) - Universidade de Brasília, Brasília, 2011.

SILVA, E. R. A. C.; GALVÍNCIO, J. D.; NASCIMENTO, K. R. P.; SANTANA, S. H. C.; SOUZA, W. M.; COSTA, V. S. O. Análise da tendência temporal da precipitação pluviométrica interanual e intra-anual no semiárido pernambucano. Revista Brasileira de Climatologia, v.22, p.76-98, 2018.

SILVA, J. V. C. L.; HIRSCHFELD, M. N. C.; CARES, J. E.; ESTEVES, A. M. Land use, soil properties and climate variables influence the nematode communities in the Caatinga dry forest. Applied Soil Ecology, v.150, p.103474-103482, 2020.

TEIXEIRA, P. C. DONAGEMMA, G. K. FONTANA, A. TEIXEIRA, W. G. Manual de métodos de análise de solo. 3.ed. Rio de Janeiro: Embrapa Solos, 2017. $573 \mathrm{p}$. 
VANDEGEHUCHTE, M. L.; SYLVAIN, Z. A.; REICHMANN, L. G.; DE TOMASEL, C. M.; NIELSEN, U. N.; WALL, D. H.; SALA, O. E. Responses of a desert nematode community to changes in water availability. Ecosphere, v.6, n.3, p.1-15, 2015.

VAUCLIN, M.; VIEIRA, S. R.; VACHAUD, G.; NIELSEN, D. R. The use of cokriging with limited field soil observations. Soil Science Society of America Journal, v.47, p.175-184, 1983.

YADAV, S.; PATIL, J.; KANWAR, R. S. The Role of Free Living Nematode Population in the Organic Matter Recycling. International Journal of Current Microbiology and Applied Sciences, v.7, n.6, p.2726-2734, 2018.

YEATES G. W.; BONGERS, T.; GOEDE, R. G. M.; FRECKMEN, D.W.; GEORGIEVA, S. S. Feedinghabits in soil nematode families and genera: an outline for ecologist. Journal of Nematology, v.25, n.3, p.315, 1993.

YEOMANS, J.C.; BREMNER, J.M. A rapid and precise method for routine determination of organic carbon in soil. Communications in Soil Science and Plant Analysis. v. 19, n.1, p.1467-1476, 1988.

ZHAO, J.; WANG, X.; WANG, X.; FU, S. Legumesoil interactions: legume addition enhances the complexity of the soil food web. Plant and Soil, v.385, n.1-2, p.273-286, 2014.

ZAVISLAK, F. D.; ARAÚJO, D. V.; MACIEL, V. A.; OLIVEIRA, K. C. L. Diversidade de nematoides em agroecossistema do algodáo no Mato Grosso. Revista Ibero-Americana de Ciências Ambientais, v.8, n.1, p.129-139, 2017. 